pharmacology and psychiatry to such relatively neglected geriatric compounds may yield better practical results.

JeROME YeSAVAGE

Department of Psychiatry and Behavioural Sciences, Stanford University School of Medicine,

Stanford, California 94305, USA

Yesavage, J A, et al, Archives of General Psychiatry, 1979, 36, 220 .

${ }^{2}$ Yesavage, J A, et al, fournal of the American Geriatric Society, 1979, 27, 80.
.

\section{What are accident and emergency departments for?}

SIR,-The accident departments that claim to have become an alternative to the surgery deserve our sympathy (6 October, p 837). I have worked for 20 years as a clinical assistant in a casualty department where the relationship between consultants and general practitioners is excellent and few patients abuse the system.

One problem is that in hospital technical expertise is not always combined with an awareness of social problems. How many accident consultants have visited their patients' homes or factories, know when the weekly bus from outlying villages runs, or know the facilities of the local surgeries?

I believe that such knowledge is essential for effective as well as humane care. Satisfactory home conditions as well as strict medical criteria are necessary before a child, for instance, is discharged home after a minor head injury. The intelligence of the mother, the proximity of a telephone, and the willingness of the general practitioner are just three factors to be considered.

Patients are sometimes brought back to the hospital when they might easily have been referred to their own doctor. A few years ago a mother and son died in a car crash near here when the latter was asked to return to a hospital 10 miles away to have sutures removed. His doctor, I know, would willingly have done this simple task for him.

General practitioners working in casualty departments can see that these social factors are not forgotten and help to narrow the gap between hospital and home care.

J V V LEWIS

Stratford-upon-Avon,

Warwickshire CV37 6LR

Disasters, flying squads, and immediate care

SIR,-The Inter-service Co-operation and Disaster Planning Subcommittee of the British Association of Immediate Care Schemes (BASICS) is currently engaged in a study of major accident plans and is reassessing the planned disaster intervention.

The article by your special correspondent (20 October, p 973) mentions the need for standardisation. We plan to standardise and clarify the expected response to a disaster situation from the medical and paramedical (ambulance) services. For example, a recent edition of the journal $B A S I C S$ carried a summary of the role of the site medical officer. Clear guidance is urgently needed now to clarify terminology and the designation of doctors to certain duties. Another urgent requirement is for standardisation of triage and casualty labelling. Every hospital and ambulance service seem to have their own ideas.
I should like to ask if readers responsible for area health authority and hospital major accident plans would be prepared to send me copies of their plans for the BASICS library, and also to enable us to extract the many good ideas and systems which have been developed locally and which deserve much better publicity. Any other comments pertaining to the medical response to a major accident would similarly be much appreciated.

K C HiNes Honorary Librarian, British Association of 69 Nottingham Road, London E10

Appendicectomy during caesarean section in a developing community

SIR,-I cannot agree with the opinion of $\mathrm{Mr}$ W O Chukudebelu and Dr W B Onuigho (18 August, p 423) that appendicectomy during caesarean section in a developing community is worthwhile, nor do I believe that they have shown it to be safe.

Appendicitis is known to be extremely uncommon in the rural African woman taking a traditional diet, which has a high fibre content. My own experience in Malawi confirms this in that I saw only one case of appendicitis in pregnancy from approximately 200000 pregnancies from which such cases would have been referred over a period of years. To see an appendicectomy scar was also a rarity.

As regards the safety of appendicectomy, the series reported included no cases of paralytic ileus and apparently none of severe puerperal sepsis. But such cases are bound to happen from time to time, especially in developing communities, and if appendicetomy has been carried out it will be a source of danger when ileus does occur, and a source of diagnostic difficulty where there is sepsis and abscess formation. Mr Chukudebelu and $\mathrm{Dr}$ Onuigho have shown the supposed safety of the procedure under teaching hospital conditions with the operation performed by a consultant obstetrician and gynaecologist. It has to be remembered that the great majority of caesarean sections in developing communities are carried out by district medical officers or mission doctors who are non-specialists and only part-time surgeons. Appendicectomy in these conditions must be less safe, and in any case such doctors have many more valuable things to be doing with their time.

To show convincingly that appendicectomy at caesarean section is worthwhile and safe it would be necessary to measure the morbidity and mortality from appendicitis in a population of adult women, and show to what extent that could be diminished by appendicectomy at caesarean section, account being taken of the morbidity and mortality associated with the procedure. This would need a series of many more than 100 cases.

Glasgow G71 6BT

C H W Bullough

\section{Appendicectomy and family history}

SIR,-In their letter (20 October, $\mathrm{p}$ 1003), Mr Lionel Gracey and Dr Stuart Sanders relate their unusual experience of operating on a pair of twins for acute purulent appendicitis on the same day, and they draw attention to the interesting fact that whereas in one of the twins a faecolith was present (acute obstructive appendicitis) this was not so in the other (acute non-obstructive appendicitis.)

I would like to suggest the strong possibility that the only reason why no faecolith was found in the one case was that it had slipped back into the caecum before the operation; a faecolith fugax. Many years ago I had the rare experience of feeling such a faecolith slip back into the caecum at operation, without any encouragement on my part, and before I had made any attempt to mobilise the caecum and appendix. But for this observation the appendix would have been regarded as another example of acute non-obstructive appendicitis, a pathological concept which I have since come to regard with suspicion.

\section{J C LEEDHAM-GREeN}

Southwold, Suffolk

\section{Fulminating meningococcal septicaemia}

SIR,-This clinical condition described in your leading article (20 October, p 953), known as the Waterhouse-Friderichsen syndrome, has salient features of sudden onset, fever, collapse, haemorrhages in the skin, and bilateral adrenal haemorrhage. This last grave feature was overlooked in your article, and there was no mention also of any postmortem findings in another contribution dealing with 10 deaths from this condition in young children (25 August, p 468) or of corticosteroids being used in their treatment, but the authors quite rightly emphasise the urgency of treatment and suggest that the medical attendant should bring the victim to hospital in his car without delay. The presence of petechiae and large ecchymoses in the skin is diagnostic in a very ill patient and the practitioner should not be misled by the absence of meningismus. The other condition that might simulate this is typhus fever.

When serving as a resident medical officer at a large infectious diseases hospital during the cerebrospinal epidemic in 1940, I saw nearly 300 cases, among them six of the fulminating variety. Although treated immediately on admission with sulphathiazole and deoxycortone acetate, they all died within a few hours of admission.

Even after nearly 40 years my clearest recollection is of the post-mortem findingsmassive haemorrhages into the suprarenals, liver, and other organs being the most striking features. We undertook our own laboratory work and I succeeded in demonstrating diplococci, two or three pairs in every highpower field in a blood film from one of these fatal cases; the memory of the technique of this escapes me, but as evidence of the overwhelming septicaemia it would appear to be unique.

The only hope of a recovery lies in early diagnosis and immediate treatment with suitable antibiotics together with steroids and treatment of shock; one should not delay by undertaking a lumbar puncture or waiting an hour for the result of a limulus endotoxin assay mentioned in a letter from America (7 April, $p$ 953). In the unlikely recurrence of a countrywide epidemic of cerebrospinal meningitis, one would expect to have an incidence of $1-2 \%$ of the fulminating variety and not many medical practitioners would come across one. 